\section{(2) OPEN ACCESS}

\title{
Recurrent chylothorax: a clinical mystery
}

\author{
Eva Otoupalova, ${ }^{1}$ Shaiva Ginoya Meka, ${ }^{1}$ Sanjay Dogra, ${ }^{2}$ Bhavin Dalal ${ }^{2}$
}

${ }^{1}$ Department of Internal Medicine, Beaumont Health System, Royal Oak, Michigan, USA

${ }^{2}$ Department of Pulmonary and Critical Care Medicine, Beaumont Health System, Royal Oak, Michigan, USA

\section{Correspondence to}

Dr Shaiva Ginoya Meka, Shaiva.Ginoya@beaumont.edu

EO and SGM contributed equally.

Accepted 3 September 2017

\section{SUMMARY}

Chylothorax is an unusual cause of pleural effusion, typically caused by trauma or malignancy. Waldenstrom's macroglobulinaemia (WM) is a clinicopathological entity demonstrating lymphoplasmacytic lymphoma in the bone marrow with an IgM monoclonal gammopathy in the blood. Recurrent chylous effusions are often resistant to conservative treatment and may require surgical intervention. We present a unique case of a 50-yearold woman with recurrent chylothorax secondary to WM that completely resolved with ibrutinib therapy. To our knowledge, this is the eighth such case reported in literature and the first case of successful resolution of chylothorax with monoclonal antibody therapy.

\section{BACKGROUND}

Pleural effusion is a common clinical problem, with estimated 1-1.5 million new cases in the USA each year. ${ }^{1}$ It is defined as an excess of fluid in the pleural cavity and is a consequence of imbalance of pleural fluid production, absorption or both. Chylothorax is a rare cause of pleural effusion that results from thoracic duct damage with chyle leakage from the lymphatic system into the pleural space. Chylothoraces contain a high concentration of triglycerides in the form of chylomicrons, lymphocytes and immunoglobulins.

Iatrogenic injury from thoracic surgery is the most common traumatic cause, while non-traumatic causes include various aetiologies such as malignancy, sarcoidosis, amyloidosis, congenital duct abnormalities and diseases of the lymph vessels such as yellow nail syndrome and lymphangioleiomyomatosis. ${ }^{2-4}$

Clinically, dyspnoea, chest pain and cough are the most common symptoms of chylothorax. Malnutrition from loss of protein and immunosuppression from loss of immunoglobulins into pleural space might lead to weight loss and infections. ${ }^{5}$

Imaging typically shows pleural effusion that is most often right-sided due to the anatomy of thoracic duct. Thoracic duct crosses from the right to left posterior mediastinum at level of T5; thus, damage to the duct above T5 typically leads to leftsided effusion, whereas damage below leads to a right-sided effusion. ${ }^{6}$

Pleural fluid appearance might be the first clue to diagnosing chylothorax. The appearance of fluid from a chylothorax is typically milky; however, it can be serous or sanguineous. ${ }^{7}$ Cholesterol pleural effusion and empyema might appear similar. Supernatant of the pleural fluid from a chylothorax typically fails to clear after centrifugation, whereas empyema fluid clears. ${ }^{8}$
Pleural fluid triglyceride level over $110 \mathrm{mg} / \mathrm{dL}$ is diagnostic of chylothorax; however, $15 \%$ of chylothoraces can have lower triglyceride levels. ${ }^{8}$ Lipoprotein electrophoresis of the pleural fluid showing chylomicrons is confirmatory in uncertain cases. ${ }^{9}$ Cholesterol is usually $<200 \mathrm{mg} / \mathrm{dL}$; higher levels are typical for cholesterol effusion. ${ }^{10}$

Treatment of chylothorax consists of treatment of the underlying aetiology, a low-fat diet and drainage. Octreotide/somatostatin and etilefrine therapy might be highly efficacious in conservative management. Recurrent chylothorax often requires surgical treatment such as thoracic duct ligation, talc pleurodesis or pleuroperitoneal shunt placement. ${ }^{11}$ Lymphatic interventions have recently emerged as a new frontier for interventional radiologists. ${ }^{12}$

Waldenstrom's macroglobulinaemia (WM) is a rare disorder with an annual incidence of approximately three per million people. ${ }^{13} 14$ It is characterised by the presence of lymphoplasmacytic lymphoma in the bone marrow with an IgM monoclonal gammopathy in the blood. Bone marrow examination in WM should demonstrate at least $10 \%$ of infiltration by small lymphocytes with lymphoplasmacytic features or lymphoplasmacytic lymphoma. The other requisite pathological feature of WM is the hypersecretion of a monoclonal IgM paraprotein. ${ }^{1516}$

Symptoms of WM are related to infiltration of haematopoietic tissues or effects of monoclonal IgM in the blood. IgM paraprotein can cause various symptoms resulting from systemic amyloidosis, paraprotein depositions in the organs, cryoglobulinaemia, peripheral neuropathy and hyperviscosity syndrome. Hyperviscosity can cause neurological symptoms such as blurring of vision, headache, vertigo, confusion, stroke or coma. About $20 \%$ to $25 \%$ of patients with WM develop peripheral neuropathy from sensory demyelination related to antimyelin-associated glycoprotein antibody.

Rituximab is commonly used as first-line treatment of symptomatic patients; however, novel immunotherapies such as recently approved tyrosine kinase inhibitor ibrutinib are emerging. ${ }^{15}$

We present a unique case of recurrent chylothorax secondary to WM. The pathogenesis of chylothorax in our case is believed to be compression of thoracic duct by an enlarged mediastinal lymph node. To our knowledge, this is the seventh such case reported in literature and the first case of successful resolution of chylothorax with monoclonal antibody therapy. 


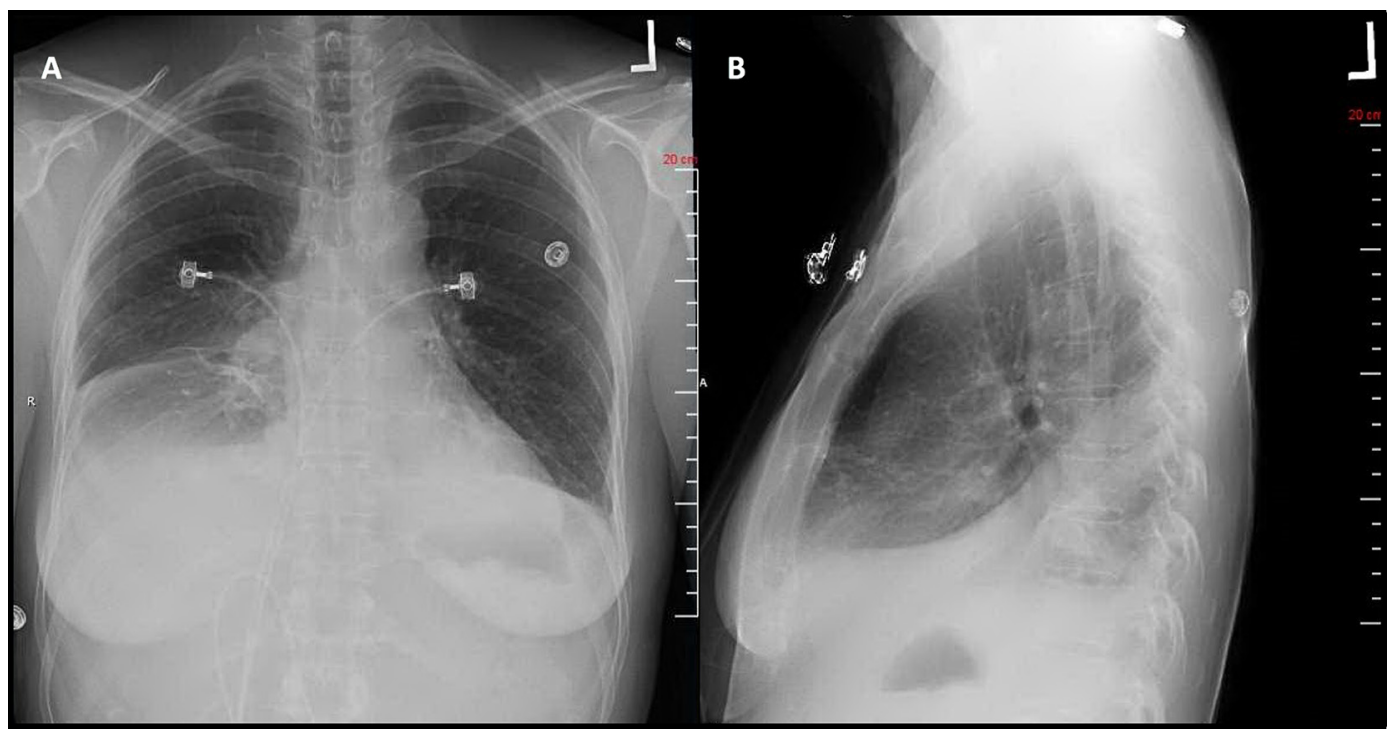

Figure 1 Chest radiography depicting the moderate right-sided pleural effusion. (A) posteroanterior view, (B) lateral view.

\section{CASE PRESENTATION}

A 50-year-old Caucasian woman presented to the emergency department with right-sided pleuritic chest that began 1 day prior. She had noted progressive dyspnoea for the past month. She denied any other associated symptoms such as fever, weight loss, fatigue, lymphadenopathy, nausea or vomiting.

Her medical history was significant for WM, discovered 3 years ago. She was found to have low-grade B-cell non-Hodgkin's lymphoma, most consistent with lymphoplasmacytic lymphoma, with 20\%-30\% bone marrow involvement and elevated serum IgM kappa levels. She was asymptomatic during these past 3 years and was observed without any specific treatment.

In the emergency department, she was found to be normotensive and did not have signs of respiratory failure. Physical examination revealed palpable adenopathy in bilateral anterior cervical as well as the left supraclavicular region. Her lung examination revealed absent breath sounds in the right lower lobe. Cardiovascular and abdominal examinations were unremarkable.

\section{INVESTIGATIONS}

Initial laboratory studies revealed total white cell count 5.8 $\mathrm{x} 109$, mild lymphopaenia $1.0 \mathrm{bil} / \mathrm{L}$, anaemia with $\mathrm{Hb} 10.2 \mathrm{~g} /$ $\mathrm{dL}$, normal renal function along with a low anion gap and low albumin. Serum protein electrophoresis revealed IgM kappa monoclonal protein with a total IgM level of $82 \mathrm{mg} / \mathrm{dL}$.

Initial chest X-ray demonstrated a right pleural effusion (figure 1). A CT chest was subsequently performed and showed a large right-sided pleural effusion with associated compressive atelectasis and slight mediastinal shift to the left. Additionally, it demonstrated adenopathy in the lower neck and upper thorax, which was increased in size compared with CT scan from 3 years ago. Lymphadenopathy was also noted at the thoracic duct, near the confluence of the left subclavian left internal jugular veins (figure 2).

\section{TREATMENT}

The patient underwent thoracentesis and $1.4 \mathrm{~L}$ of milky fluid was removed. Pleural fluid differential showed total white cell count of 13 140/mcL, red blood cell count 4000/mcL, 75\% neutrophil count, $22 \%$ lymphocytes and monocytes $3 \%$. Analysis of pleural fluid showed elevated triglycerides of $319 \mathrm{mg} / \mathrm{dL}$ consistent with chylothorax. Flow cytometry of the pleural fluid showed that $3 \%$ of total cells were monotypic B cells, expressing CD19, CD20, CD45 and kappa light chain but were negative for CD5 and CD10. The T cells (36\% of total cells) showed a CD4:CD8 ratio of 4.8:1, with normal expression of CD5. Cytology of fluid revealed moderately cellular effusion with abundant small lymphocytes mixed with a few reactive mesothelial cells. Findings were consistent with B-cell lymphoma.

\section{OUTCOME AND FOLLOW-UP}

Following thoracentesis, she had slight improvement in her shortness of breath. She was also started on a fat-free diet. However, she developed re-accumulation of pleural fluid several days later and required second thoracentesis with pigtail catheter placement. Repeat fluid analysis showed decreasing triglycerides to $94 \mathrm{mg} / \mathrm{dL}$ and negative cultures. She was discharged in stable condition; pigtail catheter was removed prior to discharge.

The patient was followed as outpatient by oncology. She underwent repeat bone marrow biopsy 1 month later, which demonstrated hypercellular marrow with $90 \%$ infiltrate of small-to-intermediate lymphocytes and plasma cells. Flow

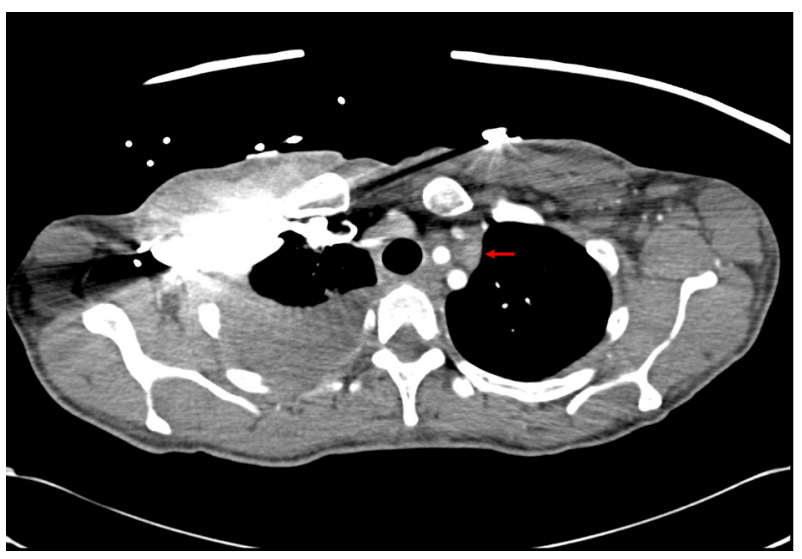

Figure 2 Chest CT demonstrating lymphadenopathy at the thoracic duct, near the confluence of the left subclavian and internal jugular veins (arrow). 
cytometry of marrow showed a population of B cells positive for CD19, CD20, CD23 and surface immunoglobulin kappa consistent with extensive infiltration by B-cell lymphoma. She was started on ibrutinib $420 \mathrm{mg}$ every night. Her pleural effusion resolved within 2 months and she did not need any further thoracentesis.

\section{DISCUSSION}

WM as a cause of chylothorax has previously been only described in seven cases in literature. ${ }^{17-23}$ In the only other case in English literature by Poisson et al, the patient was an 82-year-old man with a known diagnosis of WM and had moderate infiltration of bone marrow with lymphoma. ${ }^{17}$ Similar to our case, he presented with dyspnoea and large pleural effusion. CT imaging revealed lymphadenopathy in the left posterior costomediastinal angle associated with a predominantly left-sided effusion. He was treated with rituximab, cyclophosphamide and dexamethasone with resolution of the chylothorax.

The predominant mechanism in malignancy-induced chylothorax is thoracic duct obstruction. Mediastinal lymphadenopathy compresses the lymphatic vessels and prevents drainage of lymph from the lung periphery resulting in extravasation of chyle into the pleural space. ${ }^{24}$ However, other mechanisms might be involved. In the aforementioned case, the authors concluded that rather than obstruction of thoracic duct, direct pleural invasion of lymphoplasmacytic cells in pleura causing dilatation and proliferation of the lymph vessels might have played a role, as protein electrophoresis of chylous fluid showed the presence of pleural protein.

In our case, we believe that obstruction of the thoracic duct was the main mechanism of pleural effusion. CT revealed significant lymphadenopathy near the confluence of the thoracic duct and left subclavian left internal jugular vein. However, effusion was mostly right sided as opposed to expected left-sided effusion from presumed damage above T5; therefore, other mechanisms might have played a role.

A unique aspect of our case is that treatment with ibrutinib led to complete resolution of the effusion and symptoms. Ibrutinib is a Bruton's tyrosine kinase inhibitor recently approved by the Food and Drug Administration for the treatment of WM. A phase II trial of ibrutinib in 63 patients with symptomatic WM reported an overall response rate of 91\% (10 very good

\section{Learning points}

- Chylothorax is a rare cause of pleural effusion; it is suspected when pleural fluid has a milky appearance; pleural fluid triglyceride level $>110 \mathrm{mg} / \mathrm{dL}$ and cholesterol $<200 \mathrm{mg} /$ $\mathrm{dL}$ is diagnostic and lipid electrophoresis is confirmatory in uncertain cases.

- It is imperative to perform CT imaging and evaluate the pleural fluid for malignancy in cases of non-traumatic chylothorax.

- Along with thoracic duct obstruction by lymphadenopathy, pleural infiltration with lymphoplasmacytic cells may be an important mechanism in the pathogenesis of Waldenstrom's macroglobulinaemia (WM)-related chylothorax.

- Recurrent chylothorax related to WM may be treatable with immunotherapy agents such as ibrutinib rather than requiring surgical intervention. partial response, 36 partial response, 11 minor response, none complete). ${ }^{25}$ Such immunotherapy agents may allow treatment of WM-related-and perhaps other malignancy-relatedchylothorax without necessitating surgical intervention.

Contributors EO and SGM contributed equally to the creation of this manuscript including the acquisition of data and its interpretation/analysis. SD and BD assisted in the overall planning, revisions and providing insights to the discussion. All four authors agree to account for this manuscript.

Competing interests None declared.

\section{Patient consent Obtained.}

Provenance and peer review Not commissioned; externally peer reviewed.

Open Access This is an Open Access article distributed in accordance with the Creative Commons Attribution Non Commercial (CC BY-NC 4.0) license, which permits others to distribute, remix, adapt, build upon this work non-commercially, and license their derivative works on different terms, provided the original work is properly cited and the use is non-commercial. See: http://creativecommons.org/ licenses/by-nc/4.0/

(C) BMJ Publishing Group Ltd (unless otherwise stated in the text of the article) 2017. All rights reserved. No commercial use is permitted unless otherwise expressly granted.

\section{REFERENCES}

1 Bhatnagar R, Maskell $N$. The modern diagnosis and management of pleural effusions. BMJ 2015;351:h4520.

2 Doerr CH, Allen MS, Nichols FC, et al. Etiology of chylothorax in 203 patients. Mayo Clin Proc 2005:80:867-70.

3 Valentine VG, Raffin TA. The management of chylothorax. Chest 1992;102:586-591.

4 Nair SK, Petko M, Hayward MP. Aetiology and management of chylothorax in adults. Eur J Cardiothorac Surg 2007;32:362-9.

5 Prakash UBS. Chylothorax and pseudochylothorax. Eur Respir Mon 2002;7:249.

6 Bessone LN, Ferguson TB. Chylothorax BTH. Ann Thorac Surg 1971;12:527-50.

7 Maldonado F, Hawkins FJ, Daniels CE, et al. Pleural fluid characteristics of chylothorax. Mayo Clin Proc 2009;84:129.

8 Sassoon CS, Light RW. Chylothorax and pseudochylothorax. Clin Chest Med 1985;6:163.

9 Ryu JH, Tomassetti S, Maldonado F. Update on uncommon pleural effusions. Respirology 2011:16:238-43.

10 Huggins JT. Chylothorax and cholesterol pleural effusion. Semin Respir Crit Care Med 2010:31:743-50

11 Bender B, Murthy V, Chamberlain RS. The changing management of chylothorax in the modern era. Eur J Cardiothorac Surg 2016;49:18-24.

12 Toliyat M, Singh K, Sibley RC, et al. Interventional radiology in the management of thoracic duct injuries: anatomy, techniques and results. Clin Imaging 2017:42:183-92.

13 Fonseca R, Hayman S. Waldenström macroglobulinaemia. Br J Haematol 2007;138:700-20.

14 Groves FD, Travis LB, Devesa SS, et al. Waldenström's macroglobulinemia: incidence patterns in the United States, 1988-1994. Cancer 1998;82:1078.

15 El-Ayoubi A, Wang JQ, Hein N, et al. Role of plasma cells in Waldenström macroglobulinaemia. Pathology 2017:49:337-45.

16 Yun S, Johnson AC, Okolo ON, et al. Waldenström macroglobulinemia: review of pathogenesis and management. Clinical Lymphoma Myeloma and Leukemia 2017:17:252-62.

17 Poisson J, Aregui A, Darnige L, et al. Association of chylothorax and direct pleura involvement in a case of Waldenström's macroglobulinaemia. Age Ageing 2014;43:581-3.

18 Misaki S, Sakoda H, Hakata S, et al. [Waldenström macroglobulinemia complicated with chylothorax]. Rinsho Ketsueki 2012;53:1916-20.

19 Antón Aranda E. [Chylothorax complicating Waldenström macroglobulinemia]. Arch Bronconeumol 2001;37:155-6.

20 Monteagudo M, Lima J, Garcia-Bragado F, et al. Chylous pleural effusion as the initial manifestation of Waldenström's macroglobulinemia. Eur J Respir Dis 1987;70:326-7.

21 Martí JM, Cervantes F, Lloberes P, et al. [Chylothorax as the initial manifestation of Waldenström's macroglobulinemia]. Med Clin 1987;88:591-3.

22 Rizzo S, Campagnoli M. Chylothorax as a complication of Waldenström's disease. Eur J Respir Dis 1984;65:371-2.

23 Perreau P, Joubaud A, Joubaud F, et al. [Chylothorax in waldenstrom's disease]. Presse Med 1965:73:1641-2.

24 Nair SK, Petko M, Hayward MP. Aetiology and management of chylothorax in adults. Eur J Cardiothorac Surg 2007;32:362-9.

25 Treon SP, Tripsas CK, Meid K, et al. Ibrutinib in previously treated Waldenström's macroglobulinemia. N Eng/ J Med 2015;372:1430-40. 
Copyright 2017 BMJ Publishing Group. All rights reserved. For permission to reuse any of this content visit http://group.bmj.com/group/rights-licensing/permissions.

BMJ Case Report Fellows may re-use this article for personal use and teaching without any further permission.

Become a Fellow of BMJ Case Reports today and you can:

- Submit as many cases as you like

- Enjoy fast sympathetic peer review and rapid publication of accepted articles

- Access all the published articles

- Re-use any of the published material for personal use and teaching without further permission

For information on Institutional Fellowships contact consortiasales@bmjgroup.com

Visit casereports.bmj.com for more articles like this and to become a Fellow 